\title{
Modelos Organizacionais de Administração Pública: um estudo dos aspectos da realidade cearense na estrutura de referência das reformas do Estado
}

Maria Lucineide Serpa Gomes ${ }^{1}$ Francisco Correia de Oliveira ${ }^{2}$

\section{Resumo}

A Administração Pública Gerencial é um tema bastante debatido no Brasil e no mundo. Sua origem é historicamente datada nos anos 80 e atribuída às necessidades decorrentes das crises econômicas e fiscais que atingiram muitos países naquela década e uma resposta à crise do Estado do Bem-Estar. A resposta foi dada com a ascensão de um conjunto de abordagens que apregoavam a aplicação dos princípios de mercado e da lógica do setor privado na Administração Pública. O estudo tem como objetivo analisar a relação entre as práticas do modelo gerencial e a modernização e eficiência da administração estadual cearense. Os objetivos específicos concentram-se em apresentar os modelos de Administração Pública; identificar as reformas realizadas na Administração Pública brasileira até os dias atuais; analisar as práticas do modelo gerencial aplicadas na administração estadual cearense. A pesquisa é exploratória, de natureza qualitativa, delineada como pesquisa bibliográfica e documental. Foram realizadas entrevistas, e a partir delas foi desenvolvida a análise de conteúdo. Para a escolha dos respondentes da pesquisa de campo foi considerado o critério de ligação do entrevistado com o processo de modernização da Administração Pública estadual cearense. Assim, foram selecionados gestores, ou ex-gestores, de secretarias mais envolvidas com o processo de implementação e pesquisadores que participaram do modelo gerencial no Estado do Ceará. A contribuição deste trabalho resulta na melhor avaliação da modernização da administração estadual cearense e suas consequências.

Palavras-chave: Administração Pública. Modelo burocrático. Modelo gerencial. Resultados.

\footnotetext{
${ }^{1}$ Mestre em Administração de Empresas pela Universidade de Fortaleza (UNIFOR). Endereço: Rua Lauro Maia, 1390, Ap. 704 J. Bonifácio Fortaleza-CE-Brasil.E-mail: lucineideserpa@uol.com.br

${ }^{2}$ Professor Titular da Universidade de Fortaleza (UNFOR). Doutor em Administração. Endereço: Av. Washington Soares, 1352. Edson Queiroz. 60.851-905. Fortaleza-CE-Brasil. E-mail: oliveira@ufc.br.

Artigo recebido em: 03/06/2010. Aceito em: 27/07/2010. Membro do Corpo Editorial Científico responsável pelo processo editorial: Gilberto de Oliveira Moritz.
} 


\section{Introdução}

O presente trabalho estuda a evolução dos modelos de gestão na Administração Pública ao longo dos séculos, partindo do modelo patrimonialista até o modelo gerencial, tão decantado nos dias atuais. Procura-se, no decorrer do trabalho, dar um enfoque dessa evolução em alguns países que deram os primeiros acordes no cenário internacional, chegando ao Brasil e fechando o foco na Administração Pública cearense.

Historicamente é possível listar três tipos, ou modelos, de Administração Pública: a convencional ou administração patrimonialista; a velha gestão pública; e a nova gestão pública - a administração burocrática e o modelo emergente, conhecido como o novo serviço público ou Administração Pública Gerencial.

O modelo convencional, que foi adotado no Brasil por D. João VI no início do Século XIX com a instalação do Governo Imperial, era o tipo de administração que definia as monarquias absolutas, em que o patrimônio público e o patrimônio privado eram confundidos.

O Estado moderno, que de início foi politicamente absolutista e economicamente mercantilista, foi administrativamente patrimonialista. A monarquia se confundia com o Estado e usava os recursos fiscais para manter uma aristocracia patrimonial dependente que vivia na corte. A burocracia patrimonial era permeada por nepotismo e clientelismo, carecendo de independência política, apesar de já existirem em tais estados uma Constituição, um sistema jurídico, um serviço público e um governo.

O segundo modelo, o burocrático, surgiu com a deficiência do modelo anterior, tendo sido implantado em vários países europeus na segunda metade do Século XIX, no começo do Século XX nos Estados Unidos, e nos anos de 1930 no Brasil. A reforma burocrática, apesar de ser uma reforma administrativa, foi, essencialmente, um fenômeno político diretamente relacionado à instituição do estado de direito e do liberalismo clássico.

A reforma burocrática tornou-se necessária à modernização do Estado, além de ter se tornado politicamente inevitável. A Administração Pública Burocrática ganhou importância em função da previsibilidade e precisão no tratamento das questões organizacionais.

Weber (1999) foi um entusiasta da organização administrativa burocrática, para ele era a forma da organização que atingia o mais alto grau de eficiência. Em seu estudo sobre a Burocracia, Weber se ocupou quase exclu- 
sivamente ao que se consegue mediante a estrutura burocrática, a saber: precisão, confiança e eficiência. Ele descreve a moderna forma de legitimação que estrutura as sociedades como o poder racional-legal que se fundamenta em um conjunto de regulamentos e leis que se aplicam universalmente a uma população.

O modelo burocrático, segundo o próprio Weber (1999), prevê uma série de requisitos para o exercício da autoridade legal, e tais requisitos precisam estar presentes para a legitimação do exercício do poder. Tais requisitos devem basear-se nas seguintes ideias: que toda norma legal pode ser estabelecida por acordo ou imposição, visando fins utilitários; que todo Direito consiste em um sistema integrado de normas abstratas; que a pessoa que representa a autoridade ocupa um cargo e quem lhe obedece na verdade obedece à lei; que o dever de obediência existe apenas dentro da esfera delimitada de autoridade que lhe for conferida.

Depois da Segunda Guerra Mundial acontece o fortalecimento do Estado de Bem-Estar Social (Welfare State), tendo como objetivo principal a produção de políticas públicas na área social, de modo a garantir o atendimento das necessidades básicas da população (educação, saúde, previdência social, habitação etc.).

Nos anos de 1970 e 1980, a tendência neoliberal passou a dar ênfase à fragilidade estatal, para garantir o bem-estar social de seus cidadãos; e à fragilidade econômica gerada por tal estado. A discussão sobre a redefinição do papel do Estado, social, político e econômico, apontou para a necessidade de um novo modelo de gestão pública.

O fortalecimento da ideia de que o modelo burocrático era ineficiente para garantir o novo padrão funcional de um estado eficiente leva à ascensão do novo modelo administrativo, denominado pós-burocrático.

O terceiro modelo, a Administração Pública Gerencial, surgiu na segunda metade do Século XX, como modo de enfrentar a crise fiscal e como estratégia para reduzir o custo da máquina estatal e para tornar mais eficiente a administração dos serviços que cabiam ao Estado.

Esse modelo tem como características principais: orientação para o cidadão e para a obtenção de resultados; pressuposição de que os políticos e os funcionários públicos sejam merecedores de grau limitado de confiança; ter como estratégia a descentralização e o incentivo à criatividade e à inovação; utilização do contrato de gestão como instrumento de controle dos gestores públicos. 
A proposta da nova gestão pública é criar novas instituições e definir novas práticas que permitam transformar burocratas clássicos em gestores públicos modernos, além de criar condições para que o estado seja mais forte em termos fiscais e legitimamente democrático.

Ao novo contexto organizacional proposto pela reforma gerencial foram agregados conceitos como eficiência, eficácia e efetividade, que, por vezes, são usados de forma uniforme. A eficiência está voltada para a melhor maneira pela qual as coisas devem ser realizadas, uma relação custo/benefício, ou seja, a melhor utilização dos recursos disponíveis.

Já a eficácia pode ser entendida como o alcance dos objetivos através dos recursos disponíveis, ou seja, o alcance dos resultados. A efetividade está ligada à averiguação da real necessidade e oportunidade de determinadas ações, no caso estatal seria o aferimento dos resultados que uma ação traz de benefício à população.

Os países que tiveram mudanças mais profundas na busca dessa nova Administração Pública Gerencial, baseada nos avanços da administração de empresas, foram o Reino Unido, a Nova Zelândia e a Austrália. Nos Estados Unidos, as mudanças, respaldadas no livro de Osborne e Gaebler (Reinventando o governo), ocorreram no âmbito dos municípios e condados. Porém, desde os anos de 1980, praticamente todos os governos têm empreendido esforços para modernizar e agilizar a Administração Pública.

O movimento em busca da reforma do setor governamental, tanto nos países desenvolvidos quanto nos países em desenvolvimento, surgiu da necessidade de melhorar o desempenho do Estado, que havia crescido e que entrava em crise, quer por causas internas ou por causas localizadas além de suas fronteiras.

Existem muitas evidências de causas exógenas para a crise do Estado em geral, e para a crise do Estado brasileiro em particular. Apesar disso, o essencial da explicação e a terapia para enfrentá-la está baseado em causas endógenas. A crise do Estado é certamente mais do que uma crise fiscal, é também um conjunto de efeitos colaterais provocados por remédios utilizados para enfrentá-la, a partir de um estilo de governo caracterizado pela prioridade absoluta ao ajuste fiscal, com cortes expressivos nos gastos sociais, por exemplo.

O fato é que os problemas que suscitaram as reformas continuam a desafiar governantes e governados. Nenhuma reforma realizada nos últimos anos parece ter superado as contradições entre a necessidade de reduzir a 
interferência do Estado na vida das empresas e dos indivíduos e a urgência de resgatar sua governabilidade.

Diante do importante papel que tem a Administração Pública para o desenvolvimento do Estado, o presente trabalho se propõe a responder à seguinte questão: o modelo gerencial de Administração Pública atende aos anseios de modernização e de eficiência da Administração Pública estadual cearense?

Neste estudo busca-se responder essa questão, partindo do pressuposto básico de que as características da realidade estadual cearense negam a validade universal do modelo gerencial. Para testar tal pressuposto foi realizada uma análise na Administração Pública cearense com a finalidade de identificar as práticas gerenciais adotadas pelo governo estadual e, a partir de tais práticas, avaliar se elas geraram em solo cearense os resultados esperados de um governo moderno orientado para seus cidadãos.

Com o intuito de explorar essa questão, este trabalho se desenvolveu com o objetivo de analisar a relação entre as práticas do modelo gerencial e a modernização e eficiência da administração estadual cearense. O presente trabalho é uma pesquisa qualitativa de caráter exploratório com estudo na Administração Pública estadual cearense, utilizando entrevistas para obtenção de dados para análise, além de pesquisa documental.

Entrevistas com gerentes estaduais e com pesquisadores da área de Administração Pública ajudaram na identificação dos entraves à modernização da Administração Pública Brasileira, e, no caso em estudo, na Administração Pública do Estado do Ceará.

A partir do material recolhido com as entrevistas foi realizada uma análise de conteúdo. O método de análise de conteúdo presta-se tanto para fins exploratórios, quanto para verificação, confirmando ou refutando hipóteses ou suposições estabelecidas.

\section{Modelos Organizacionais da Administração Pública}

A Administração Pública se desenvolveu através dos séculos dentro de três modelos básicos: a patrimonialista, a burocrática e a gerencial. O patrimonialismo pode ser definido resumidamente como a confusão entre o que é público e o que privado. O conceito de patrimonialismo foi introduzido por Weber (1999) referindo-se a uma variante da dominação tradicio- 
nal baseada na "crença na santidade de ordens e poderes senhoriais tradicionais” (MARTINS, 1997; COSTA, 2007; WEBER, 1999).

A Administração Pública Patrimonialista era caracterizada pela incapacidade ou relutância do administrador em distinguir o patrimônio público de seus bens privados. $\mathrm{O}$ aparelho estatal era tratado como uma extensão do poder do soberano. Esse modelo teve início na Idade Média, predominando nas monarquias absolutistas dos Séculos XV ao XVII, tendo chegado ao fim no Século XIX, quando foi substituído pelo modelo burocrático weberiano (PEREIRA, 2006; FROES; MELO NETO, 2006).

Uma das decorrências do modelo patrimonial é que a corrupção e o nepotismo são facilitados por esse tipo de administração. Outras consequências decorrem do fato de o patrimonialismo afetar a finalidade básica do Estado de proteger a coisa pública, pois as atividades públicas deixam de estar empenhadas com a melhor relação custo-benefício possível para a sociedade. Assim, desloca-se o foco de atenção da sociedade para as questões que privilegiam o interesse de poucos.

Torna-se então necessário desenvolver uma administração em que não apenas haja uma clara distinção entre o público e o privado, mas também que estabeleça a separação entre o político e o administrador público. É a partir disso que surge a administração burocrática racional-legal moderna ou modelo burocrático.

Como o Estado era pequeno e tinha como única função a garantia da propriedade e dos contratos, a questão da eficiência não era fundamental, mas, no momento em que o Estado cresceu e se converteu em um Estado social e econômico, assumindo um grande número de serviços sociais e econômicos, o problema econômico passou a ser importante.

Com a ascensão do capitalismo e da democracia estabeleceu-se uma clara distinção entre a res publicae ("a coisa pública") e os bens privados. Democracia e Administração Pública Burocrática surgiram com o intuito de proteger o patrimônio público contra a privatização do Estado.

A Democracia foi o instrumento político que resguardou os direitos civis contra a tirania, e a Burocracia foi o instrumento administrativo para combater o nepotismo e a corrupção, adotando princípios de um serviço público profissional e de um sistema administrativo impessoal, formal e racional. A administração burocrática veio substituir as formas patrimonialistas de gestão, ganhando importância pela previsibilidade e precisão no tratamento das questões organizacionais (PEREIRA, 2006). 
O termo burocracia foi empregado pela primeira vez no Século XVIII, por Gournay, designando o corpo de funcionários e empregados do Estado absolutista francês, sob dependência do soberano e incumbido de funções especializadas. Outra faceta do termo burocracia foi detalhada no Século XIX por Weber, a partir de estudos sobre o aparelho administrativo prussiano que era organizado de forma hierárquica e monocrática. Entretanto, o modelo burocrático já era difundido nas administrações públicas, nas organizações religiosas e militares, especialmente na Europa (ARAGÃO, 1997).

Weber (1999) trabalhou com a sociologia política e não com a teoria das organizações. Para ele a burocracia é um tipo de poder. É igual à organização. É um sistema racional cuja divisão se dá racionalmente visando determinados fins. A burocracia para ele implica na preponderância do formalismo, na existência de normas escritas, na estrutura hierárquica, na divisão horizontal e vertical de trabalho e impessoalidade e no recrutamento do pessoal (ARAGÃO, 1997; TRAGTENBERG, 2006).

Três características são basilares no modelo burocrático: a formalidade, a impessoalidade e o profissionalismo. A formalidade impõe deveres e responsabilidades aos que formam a organização, assim como configura e legitima a hierarquia administrativa, os procedimentos administrativos, a formalização dos processos e a formalização das comunicações, tanto internas quanto externas.

A impessoalidade preceitua que a relação entre os membros da organização e entre organização e ambiente externo deve basear-se em funções e linhas de autoridade claras. Clara também deve ser a convicção de que as posições hierárquicas pertencem à organização, e não ao ocupante da posição.

O profissionalismo está diretamente ligado ao valor dado ao mérito como critério de justiça e diferenciação. Uma competição justa mostra as capacidades técnicas e o conhecimento do indivíduo. O profissionalismo ideal está baseado em uma hierarquia de competências com base na meritocracia. Outro valor do modelo burocrático é a equidade, que dá aos empregados um tratamento igualitário por desempenharem tarefas iguais.

Tais características, para Weber (1999), tornam a burocracia capaz de um alto grau de eficiência. Entretanto, o modelo weberiano recebeu críticas, como a de Lane (1993), que argumenta que o pressuposto da impessoalidade na verdade dissimula as reais motivações dos burocratas. 
Isso (a transição de uma relação pessoal para uma impessoal) pode ser um passo no sentido de uma maior eficiência no sentido absoluto. Entretanto, temos aqui uma espécie de falácia: o fato de um burocrata ser dedicado ao seu cargo não implica que o problema da motivação está resolvido; pode ser que ele seja assim dedicado porque maximiza sua utilidade pessoal, ou porque deseja ser útil no trabalho. Estes dois objetivos não podem garantir eficiência (LANE, 1993, p. 50).

Outras críticas dizem respeito à inadequação de uma análise real das estruturas organizacionais, a partir do modelo ideal descrito por Weber (1999); $e$ à afirmação de que o tipo ideal consiste em um esquema conceitual que mistura a descrição de características que definem burocracia a uma série de hipóteses, dentre elas a de maximização da eficiência organizacional (ARAGÃO, 1997).

A questão da eficiência das burocracias recebe as seguintes críticas: a adesão incondicional dos servidores às normas leva ao ritualismo e à ineficiência; a hierarquização e a centralização prejudicam a eficiência, pois tendem a distorcer as informações; a centralização limita a capacidade de iniciativa dos subordinados.

Robert Merton (1949) elaborou a crítica mais incisiva e direta ao modelo burocrático, analisando os seus efeitos negativos sobre as organizações e outras esferas da vida. Esses efeitos negativos foram chamados de disfunções burocráticas: o impacto da prescrição estrita de tarefas (red tape) sobre a motivação dos empregados, resistência às mudanças, e o desvirtuamento de objetivos provocado pela obediência acrítica às normas (SECCHI, 2009, p. 353).

A burocracia controlou bastante o nepotismo e a corrupção mais visíveis do que o patrimonialismo, entretanto, os direitos civis e sociais continuaram sem proteção. Na verdade muito nepotismo e corrupção ainda conviviam com a burocracia.

Se, no século XIX, a Administração Pública do Estado liberal era um instrumento para garantir os direitos de propriedade - assegurando a apropriação dos excedentes da 
economia pela classe capitalista emergente -, no estado desenvolvimentista, a administração burocrática era uma modalidade de apropriação dos excedentes por uma nova classe média de burocratas e tecnocratas (PEREIRA, 2006, p. 27).

O fato é que enquanto se viveu em um ambiente caracterizado por poucas mudanças ou por mudanças razoavelmente estruturadas e previsíveis, dominado por certo determinismo e linearidade, o problema da gestão reduzia-se a, simplesmente, olhar para trás, descobrir as leis de formação das variáveis relevantes da organização, construir um modelo explicativo para essas variáveis e projetar o futuro. Nessa situação baseada em uma razoável estabilidade, o modelo burocrático atendia às necessidades, já que seus princípios eram compatíveis com o contexto.

A partir da década de 1970, o Estado, pautado no modelo burocrático, foi exposto a questionamentos que o colocaram em xeque. A chegada das inovações tecnológicas, vindas com a globalização, enfraqueceu os controles governamentais existentes. O modelo burocrático, com rígidos controles e procedimentos, não mais atendia às necessidades da Administração Pública.

Surge, então, o modelo gerencial de Administração Pública, como uma busca de excelência administrativa e foco no cidadão. Com o modelo gerencial, a capacidade de gestão toma o centro da discussão da Administração Pública. Questões como o ajuste fiscal e procedimentos voltados para o mercado são inseridos nessa discussão.

A necessidade de aumentar a eficiência do Estado passou a ser um imperativo do processo de globalização, que intensificou a competição entre países. Com o intuito de solucionar tal problema, emerge, na segunda metade do Século XX, a Administração Pública Gerencial.

Existem várias terminologias que denominam o Novo Gerencialismo: Nueva Gestión Pública - NGP ou New Public Management - NPM (DUNLEAVY; HOOD, 1994) ou Nova Administração Pública - NAP (FERLIE et al., 1999).

O Novo Gerencialismo é uma tendência hegemônica que está influenciando as práticas organizacionais dos serviços públicos, incorporando a lógica concorrencial e levando ao abandono dos sistemas baseados na rígida hierarquia burocrática. 
Entretanto, as mudanças buscadas e as alcançadas não ocorrem em um vazio histórico ou sem um contexto estrutural. Na esfera pública, as mudanças estão sempre relacionadas às mudanças no padrão de desenvolvimento, e todo padrão de desenvolvimento apresenta três aspectos: uma forma de organização de trabalho, uma estrutura macroeconômica e um modo de regulação (MENDES; TEIXEIRA, 2000).

Para a OCDE (Organization for Economic Co-operation and Development), os desafios que levaram e têm levado tantos países pelo caminho da reforma pública podem ser identificados entre os seguintes: limitações fiscais; busca intensiva de formas mais efetivas para a implantação de políticas públicas; pressão de grupos empresariais para promover um setor público direcionado para o mercado; mudança de valores que questionam a Administração Pública, tanto interna quanto externamente; mudanças tecnológicas que aprimoraram a difusão das informações; mudanças nos perfis sociodemográficos das populações.

A despeito da tendência mundial de reformar a Administração Pública, o termo Nova Gerência Pública (New Public Management), apesar de novo, tem elementos não tão novos assim, como a criação das agências na administração estatal, que já existiam na administração alemã nos anos de 1970. Tal modelo também não tem uma receita única em todos os países, antes, ele assume uma variedade de formas, dependendo das preocupações e necessidades nacionais.

Não existe um modelo único que aborde e resolva todas as necessidades de cada país, visto que cada reforma deve ter raízes na configuração histórica e nas tradições de cada nação, nas estruturas legais, nas forças políticas e administrativas, nas perspectivas econômicas e sociais e na posição internacional do país (ORMOND; LÖFFLER, 1999).

As nações não devem ficar presas a conceitos e receitas de nova administração, nem a preconceitos da antiga Administração Pública. O modelo único e perfeito jamais existirá em uma forma ideal.

Uma questão muito discutida no modelo gerencial é a implicação para as relações de responsabilidades (accountability) entre os gerentes públicos, os servidores, os ministérios, as secretarias, as autoridades políticas, os cidadãos, o Poder Legislativo e o Poder Executivo. Na gestão gerencial, o comprometimento com o resultado tornou-se um instrumental que promoverá mecanismos de responsabilidade. 
Os mecanismos de responsabilidade correspondentes serão compatíveis com as idéias básicas da gerência de desempenho, que inclui a tarefa de estabelecer expectativas do desempenho, o registro da informação confiável a respeito do que foi alcançado, a necessidade de avaliar se as expectativas prévias foram satisfeitas, e a necessidade de oferecer retroalimentação sobre o desempenho alcançado, mantendo a responsabilidade por meio de incentivos positivos ou de sanções negativas (ORMOND; LÖFFLER, 1999).

Para o Centro Latino Americano de Administração para o Desenvolvimento (CLAD, 1998), a reforma gerencial que ocorreu em diferentes países, apesar de possuir diversas características comuns, não teve um sentido unívoco, um único paradigma que guiasse todas as nações.

A Administração Pública Gerencial pode ser considerada um sistema baseado na racionalidade instrumental aplicada à gestão pública, tendo como preceitos organizacionais: a desagregação do serviço público em unidades especializadas e centros de custos; competição entre organizações, tanto públicas quanto privadas; o uso de práticas de gestão advindas da administração privada; atenção à disciplina e economia; administradores empreendedores; avaliação nos outputs (POLLITT; BOUCKAERT, 2002; HOOD, 1995).

O modelo gerencial, ou pós-burocrático, na verdade é constituído não por um modelo único, mas pela Administração Pública Gerencial (APG), pelo Governo Empreendedor (GE) e pela Governança Pública. A Administração Pública Gerencial (APG), ou Nova Gestão Pública (New Public Management), é um modelo normativo pós-burocrático, baseado nos valores de eficiência, eficácia e competitividade.

O Governo Empreendedor compartilha as ideias de produtividade, orientação ao serviço, descentralização, eficiência na prestação de serviços, uso de mecanismos de mercado e accountability. A New Public Management (NPM) foi um movimento de mudanças na Administração Pública que atingiu as administrações do norte da Europa, do Canadá e da Oceania, nos anos de 1980 e 1990 (KETTL, 2006; SECCHI, 2009).

O GE foi inaugurado como modelo de gestão, a partir da publicação do livro Reinventando o Governo, de Osborne e Gaebler, em 1992. No livro, que se tornou uma bíblia de muitos gerentes públicos ao redor do mundo, os autores apresentam o GE sintetizando-o em dez mandamentos, a saber: go- 
verno catalisador; governo que pertence à comunidade; governo competitivo; governo orientado por missões; governo de resultados; governo orientado ao cliente; governo empreendedor; governo preventivo; governo descentralizado e governo orientado para o mercado (SEABRA, 2001).

$\mathrm{O}$ modelo denominado de Governança Pública trata-se de um resgate da política na Administração Pública, minimizando a importância de critérios técnicos nos processos de decisão e um reforço de mecanismos participativos de deliberação na esfera pública, além de um modelo de relação entre atores públicos e privados na elaboração de políticas públicas. Exemplos básicos de GE são as Parcerias Público-Privadas - PPPs (SECCHI, 2009).

Entretanto, apresentar os modelos de forma fragmentada leva à errônea ideia da total independência entre eles. Além dos elementos que os distinguem, os modelos compartilham elementos comuns, tal como a preocupação com a função controle. No modelo burocrático weberiano, a formalidade e a impessoalidade servem para controlar os agentes públicos, as comunicações, as relações intraorganizacionais e as da organização com o meio ambiente.

Nos modelos gerenciais (Administração Pública gerencial e governo empreendedor), a função controle está presente, tanto na capacidade de controle dos políticos sobre a máquina administrativa, quanto no controle de resultados das políticas públicas. No governo empreendedor, o controle é desenvolvido pelo envolvimento de atores não estatais no processo de elaboração de políticas públicas (SECCHI, 2009).

Um ponto em comum nos modelos burocráticos e gerenciais é a separação entre política e administração. No modelo weberiano, cabe à política o processo de construção de uma agenda pública, enquanto a implementação da política pública cabe à administração.

Nos modelos gerenciais, a responsabilidade sobre os resultados das políticas públicas é da alçada dos políticos, apesar de que aqui a distinção entre política e administração é suavizada quando evoca o envolvimento da sociedade e de burocratas na construção das políticas públicas.

Quanto à centralização e liberdade de decisão dos gestores, enquanto na burocracia weberiana a discricionariedade, por parte dos gestores, é evitada, no gerencialismo, é dado ao gestor público liberdade de decisão, assim, ao invés de controlar o processo, é realizada a avaliação dos resultados.

O tratamento dado ao cidadão é uma clara distinção entre os modelos: no modelo burocrático, ele é chamado de usuário dos serviços públicos; nos modelos gerenciais, ele é tratado como cliente, cujas necessidades devem 
ser satisfeitas pelo serviço público; para a governança pública, os cidadãos, assim como outras organizações, são chamados de parceiros ou stakeholders.

\section{A Administração Pública no Brasil}

A formação e o desenvolvimento do Estado brasileiro tiveram suas raízes no período colonial, sob influência da Coroa portuguesa, quando existia uma relação tutelar entre o Estado e a nação. Nos anos de 1930 se dá o nascimento do Estado Burocrático, um Estado fortemente centralizador e intervencionista, e de uma classe empresarial ainda muito dependente de autorizações, proteções e favores estatais.

Durante a ditadura Vargas, a Administração Pública Burocrática demonstrou ser uma consequência da emergência de um capitalismo moderno no Brasil. O Estado assumiu a liderança do processo de modernização econômica e social do país, intervindo na produção e criando um modelo desenvolvimentista. O Estado Burocrático veio combater o patrimonialismo anteriormente vigente.

Apesar de ser, inicialmente, eficaz e alcançar excelentes níveis de desenvolvimento durante muitos anos, o modelo burocrático passou a se tornar obsoleto devido à influência de fatores externos e internos a partir da crise do petróleo na década de 1970, quando uma grave crise econômica mundial findou os anos prósperos que se seguiram após a Segunda Guerra Mundial.

Os governos perceberam que ao invés de um modelo burocrático, rígido e intervencionista deveria se trabalhar na criação de um modelo gerencial, o que aconteceu inicialmente na Grã-Bretanha, Estados Unidos, Austrália, Nova Zelândia e depois, gradualmente, na Europa e Canadá.

No Brasil, em 1980, o modelo burocrático, em plena ditadura militar já se encontrava completamente atrasado. Nessa década, o crescimento econômico estagnou e surgiu a ideia do Estado Mínimo, devendo manter apenas a ordem através da educação, da saúde e da segurança, e administrando a justiça.

A partir de 1990, o Estado brasileiro se vê diante da realidade da competição global, caracterizada pela abertura dos capitais e comércio internacionais, associada à privatização das empresas estatais e à redução da influência do Estado na economia. Começa assim a redefinição do papel do Estado, de um modelo paternalista, empresarial e burocrático para um papel de gestor. 
Nesse contexto, a Administração Pública Gerencial, também conhecida como nova Administração Pública, emergiu como o modelo ideal para o gerenciamento do Estado brasileiro reformado pela sua adequação ao diagnóstico da crise do Estado realizado pela aliança social liberal e por seu alinhamento em relação às recomendações do Consenso de Washington para os países latino-americanos.

Analisando a reforma dos anos de 1990, é possível identificar duas vertentes: uma gerencial, alinhada ao movimento internacional capitaneado, sobretudo, pelo Reino Unido e pelos Estados Unidos, e uma societal que herdou as ideias e propostas dos movimentos contra a ditadura e pela redemocratização no Brasil, nas décadas de 1970 e 1980 (PAULA, 2008).

A Administração Pública societal se baseia em experiências alternativas de gestão pública implantadas no âmbito do poder local no Brasil, a partir do reconhecimento dos conselhos gestores e orçamentos participativos. Suas raízes estão nos movimentos dos anos de 1970 e 1980 e nas políticas implantadas pelos governos das frentes populares dos anos de 1990, formadas pelos partidos de esquerda e pelo Partido dos Trabalhadores. Seu projeto de erguer uma gestão pública social ganhou nova dimensão com a vitória da aliança popular-nacional nas eleições presidenciais de 2002.

Os movimentos mobilizadores no Brasil datam do período colonial, mas alcançaram seu ápice na década de 1960, no governo de João Goulart, quando foram reprimidos pelo Golpe de 1964. Emergiram nos anos de 1970, propondo uma Administração Pública mais aberta à participação popular, e nos anos de 1980 eclodiu a vertente societal de reforma e gestão do Estado.

O tema cresceu no período de elaboração da Constituição de 1988, quando diferentes forças políticas apresentaram propostas para elaboração de um novo referencial entre Estado e sociedade, na intenção da construção de uma sólida democracia no Brasil. O movimento envolvia sindicatos, pastorais, movimentos populares, partidos de esquerda e ONGs, além de setores acadêmicos e entidades profissionais, como a OAB - todos centrados na reivindicação da cidadania e no fortalecimento do papel da sociedade civil na vida política do país (PAULA, 2008).

A despeito da heterogeneidade do campo dos movimentos, uma concepção começou a se tornar predominante no âmbito da vertente societal: a implementação de um projeto político que procura ampliar a participação dos 
atores sociais na definição da agenda política, criando instrumentos para exercer um maior controle social sobre as ações estatais e desmonopolizando a definição $e$ implementação das ações públicas. Consolidava-se assim a visão que orienta o discurso da vertente societal: a reforma do Estado não é somente uma questão administrativa e gerencial, mas sim um projeto político (PAULA, 2008, p.155).

Multiplicaram-se ao longo dos anos de 1990 pelo país governos com essa proposta inovadora de gestão, principalmente nos governos das frentes populares. Os principais pontos positivos encontrados nessas experiências são: a busca de elaboração de um projeto de desenvolvimento que atenda aos interesses nacionais; e a construção de instituições políticas e políticas públicas mais abertas à participação social e voltadas às necessidades dos cidadãos.

\section{A Administração Pública no Estado do Ceará}

No final da década de 1980, o Ceará destacou-se no quadro nacional por romper com um modelo oligárquico de poder que perdurava por décadas, não apenas neste estado, mas em outros estados do Nordeste brasileiro. As condições para o desencadeamento de tal ação foram sendo criadas à medida que o Estado perdia a competência para responder aos interesses da burguesia local.

O rompimento, diferentemente do que aconteceu em estados como a Bahia e Pernambuco, deveu-se a um movimento capitaneado por jovens empresários cearenses preocupados com o destino econômico estadual. Tais empresários formavam um grupo com raízes e interesses no próprio estado, inquietados com o desequilíbrio das finanças estaduais viram no rompimento com a classe política tradicional o caminho para o desenvolvimento econômico do Ceará e de seus próprios interesses.

Nas duas décadas que se seguiram, o Ceará entrou em uma fase marcada por políticas de atração de investimentos e a busca de implantação de uma agenda de reformas administrativas, visando criar uma Administração Pública que efetivamente funcionasse, gerando resultados para o Estado e para a sociedade cearense. 
O Ceará adiantou a agenda modernizadora que o Brasil entraria anos depois, inclusive envolvendo-se em pontos cruciais para seu desenvolvimento econômico, e organizando suas finanças antes mesmo da vigência da Lei de Responsabilidade Fiscal do ano 2000.

Um aspecto importante da organização do Estado deveu-se também à ênfase técnica dada à formação dos secretariados, sobretudo em áreas definidoras das políticas de desenvolvimento econômico. Essa foi uma inovação acompanhada por outros estados que também se utilizaram da estratégia de administrar a política e a economia por critérios diversos.

É necessário que se perceba que o contexto que propiciou o avanço das reformas e também o sucesso do ajuste fiscal cearense contou com aspectos da conjuntura nacional, como a forte descentralização dos recursos antes concentrados na União, e com a estabilização da inflação

O movimento para modernizar a Administração Pública foi, e continua sendo, um movimento mundial que alcançou a máquina do governo federal brasileiro, e a partir disso, os estados da federação. O Ceará partiu para a modernização por motivos semelhantes aos ocorridos em outras partes do mundo, a saber: buscar a otimização dos recursos públicos; priorizar esforços para melhorar os resultados das ações governamentais; reduzir custos e partir para a visão do cidadão, agora muito mais informado e crítico, como cliente.

O governo de 2003 buscou na experiência canadense um referencial para colocar em prática a administração por resultados ou governo empreendedor. O governo atual implementa muitas outras ações, mas seu foco também é o governo por resultados.

\section{Análise dos Resultados da Pesquisa}

As entrevistas foram realizadas com gestores e um ex-secretário do atual Governo estadual cearense. Dos gestores, dois são secretários, um faz parte da secretaria responsável pela arrecadação e administração financeira do Estado e o outro é da secretaria responsável pelo planejamento e gestão do Governo; o terceiro está na secretaria executiva da Secretaria de Governo e outro responde pela instituição que realiza os estudos socioeconômicos estaduais.

O ex-gestor está nesta posição por ter se afastado recentemente devido à exigência da atual Lei Eleitoral, uma vez que sendo candidato não pode ocupar cargos públicos em época de eleição. Os dois pesquisadores presta- 
ram serviços para o Instituto de Pesquisa e Estratégia Econômica do Ceará IPECE, e um deles foi pessoalmente treinado pelo Banco Mundial na ocasião da Operação SWAP, tornando-se posteriormente um disseminador dos princípios da Gestão por Resultados para dezenas de gestores estaduais cearenses.

As entrevistas foram, em sua maioria, respondidas por gestores, vinculados aos seguintes órgãos: Secretaria da Fazenda - SEFAZ, Secretaria de Planejamento e Gestão - SEPLAG, Secretaria de Saúde - SESA, Gabinete do Governador - GABGOV e Instituto de Pesquisa e Estratégia Econômica do Ceará - IPECE.

As falas foram extraídas das respostas às questões das entrevistas, nas quais os respondentes tiveram oportunidade de expressar abertamente seus pensamentos em relação ao modelo gerencial aplicado à administração pública estadual cearense. Ressalta-se que por terem sido utilizadas questões abertas, essas questões não foram direcionadas especificamente para cada categoria.

A análise dos resultados está dividida em quadros de acordo com cada categoria, características e falas dos sujeitos das entrevistas. O Quadro 1 foi elaborado com o intuito de facilitar a visualização das categorias e das características apresentadas na análise dos resultados.

\begin{tabular}{|c|l|}
\hline \multicolumn{1}{|c|}{ Categoria } & \multicolumn{1}{c|}{ Característica } \\
\hline \multirow{4}{*}{ Cultura gerencial } & Necessidade de implantação do modelo gerencial \\
\cline { 2 - 2 } & Ênfase na eficiência e nos resultados \\
\cline { 2 - 2 } & Práticas gerenciais do setor privado \\
\cline { 2 - 2 } & Obstáculos \\
\hline \multirow{2}{*}{ Foco no cliente } & Transparência nas informações prestadas pela administração \\
\cline { 2 - 2 } & Conhecimento de seu papel no processo de modernização \\
\hline \multirow{2}{*}{ Papel do servidor } & Avaliação de desempenho \\
\cline { 2 - 2 } & Conhecimento de seu papel no processo de modernização \\
\hline Controle fiscal & Equilíbrio fiscal \\
\hline
\end{tabular}

Quadro 1: Categorias de análise e suas características Fonte: Dados primários 


\section{Conclusão}

De acordo com as falas dos entrevistados, a administração cearense tem se regido pela busca de resultados, estabelecimento de metas, controles e pelo acompanhamento por meio de indicadores. Constatou-se também o conhecimento de todos de que o foco do modelo adotado deve ser o cidadão e que sua participação é necessária para o êxito da administração gerencial.

Entretanto, percebeu-se que $43 \%$ dos entrevistados observou que o maior obstáculo para a implantação da Nova Administração Pública é a própria característica local de resistência criada pelas pessoas que fazem parte da máquina administrativa. Assim, o maior desafio para a implantação da modernização administrativa é a cultura organizacional ainda existente.

Essa cultura da organização pública pode ser considerada uma herança patrimonialista e, apesar das mudanças que ocorreram no país, o nepotismo, o favoritismo, a corrupção e o clientelismo ainda são características culturais persistentes na sociedade, com relação ao Estado e também à organização da Administração Pública.

Quanto ao papel do cidadão/cliente/usuário é unânime entre os entrevistados que, apesar de já sentirem o reflexo de uma administração mais eficiente, eles não têm conhecimento da existência, na administração estadual, de um modelo cujo foco deva ser o cidadão.

A falta de engajamento da sociedade ao modelo atual da administração do Estado do Ceará deve-se, sobretudo, à falta de repasse de informações aos cidadãos sobre as mudanças de paradigmas do Governo estadual. O Governo conta com instrumentos de apresentação de informações (por exemplo, o Portal da Transparência), mas ainda não existe uma divulgação abrangente da sua existência e de outros canais de comunicação entre o Governo e o cidadão.

Quanto à importação do modelo gerencial da administração canadense, por meio de pesquisa bibliográfica constatou-se a existência de semelhanças entre as características do modelo canadense e o cearense. Ressaltese que segundo o entrevistado E3, o modelo canadense já é um modelo maduro, uma vez que está em prática há 30 anos. Entretanto, uma divergência diz respeito exatamente à intensidade da participação popular no processo, na elaboração e no acompanhamento dos programas e das políticas governamentais. 
Quanto ao comprometimento do servidor no processo de Gestão por Resultados, é mencionada a questão do treinamento dos gestores na implantação da GPR. Assim, entende-se que é repassada, para a grande massa dos servidores, a necessidade de alcançar metas e a avaliação a que ele será submetido, mas não existe um conhecimento a respeito das mudanças não apenas dos processos, mas, as mudanças conceituais da organização gerencial. Não há, na verdade, uma divulgação do modelo, nem para o público interno, nem para o externo.

No modelo em vigor no Ceará, ainda percebe-se a necessidade de definir a responsabilização (accountabillity) dos gestores públicos, apesar de já haver uma preocupação, por parte do Governo estadual, desde a criação da Secretaria da Controladoria em 2003.

O modelo gerencial, não apenas no Canadá, mas nos demais países que já estão no processo de modernização da Administração Pública desde meados da década de 1980, tem características próprias que são reflexos de cada país, apesar de manter seus conceitos básicos.

No Ceará, apesar de já se estar em busca de uma administração mais eficiente desde o ano de 1987, ainda não há uma consciência interna e da sociedade, mas não há dúvidas de que há um conceito de cidadania ativa em construção. $\mathrm{O}$ modelo está razoavelmente estruturado e em fase de maturação, já que metas e estratégias estão sendo traçadas pela Secretarias. A questão da avaliação de desempenho ainda é incipiente, mas foi verificada a percepção, por parte, não apenas dos gestores, mas de todos os entrevistados, de que a adoção do modelo trouxe ganho para a administração estadual cearense, sobretudo na racionalização de gastos, no acompanhamento dos resultados do Governo e no foco de atingir resultados que sejam significativos em termos sociais e econômicos.

Ressalte-se a necessidade de romper a cultura organizacional tradicional dos clientes internos da administração local do Estado. As mudanças não foram bem recebidas por uma parcela dos gestores e/ou de servidores. O sucesso da implementação do modelo passa pela compreensão e envolvimento de todos que formam a administração, a partir da mudança da cultura patrimonialista ainda existente. Para tal, é necessária a capacitação profissional em todos os níveis da organização.

Uma proposta de avanço para a administração local passa pela melhoria na consistência e divulgação das informações, para acompanhamento dos resultados do Governo; ampliação, discussão e divulgação do modelo de 
gestão para promover uma maior conscientização dos servidores e da sociedade; capacitação do servidor; melhoria nos processos; intensificação na cobrança de resultados e na accountability.

\section{Organizational Models of Public Administration: a study of some aspects of the reality derived from Ceara State reform. Ouvir Ler foneticamente}

\section{Abstract}

The new public management is a much-debated issue in Brazil and in many other countries worldwide. Its origin is historically dated in the 80's, attributed to State economic and fiscal crises that had reached many countries in that decade and was also a response to State Welfare deterioration. The answer given prescribed a set of policies that proclaimed the application of market principles and private sector logic to the Public Administration. The study has as the objective to analyze the relation between the new public model practices and the modernization and efficiency of the State administration. The specific objectives are concentrated on presenting the models of Public Administration; on identifying reforms carried through in Brazilian Public Administration until the current days; on analyzing managerial practices of the new model applied to state administration. This is an exploratory, qualitative and documentary research. Interviews had been carried out, and then, the study made use of the technique of content analysis. To choose the respondents in the field research, the study considered the criterion of linking the interviewee to the process of modernization of the Public Administration. Thus, managers, former-managers of the main state secretariats involved with modernization of public administration, and researchers who had previously taken part in this process were selected. The contribution of this work results in a better evaluation of the modernization of the state Administration and also of its consequences.

Key words: Public administration. Bureaucratic model. Managerial Public. Administration model. 


\section{Referências}

ARAGÃO, Cecília Vescovi. Burocracia, eficiência e modelos de gestão pública: um ensaio. In: RSP - Revista do Serviço Público, Ano 48, n. 3, set/dez, Brasília: ENAP - Escola Nacional de Administração Pública, 1997.

COSTA, Frederico Lustosa da. Condicionantes da reforma do Estado no Brasil. In: MARTINS, Paulo Emílio Matos; PIERANTI (Orgs). Estado e Gestão Pública. Visões do Brasil Contemporâneo. Rio de Janeiro: Editora FGV, 2007.

FERLIE, E.; ASBURNER, L.; FITZGERALD, L.; PETTIGREW, A. A nova administração pública em ação. Brasília: ENAP, 1999.

FROES, César; MELO NETO, Francisco Paulo. Administração Pública. Rio de Janeiro: UCB/EB, 2006.

HOOD, Christopher. The "new public management" in the 1980s: variations on a theme. Accounting, Organizations and Society, v. 20, n. 2/3, p. 93-109, 1995. Disponivel em: <http://www.scielo.br/scielo.php?pid=S0034$122009000200004 \&$ script $=$ sci_arttext $>$. Acesso em: 15 dez. 2009.

KETTL, Donald F. A revolução global: reforma da administração do setor público. In: PEREIRA, Luís Carlos Bresser; SPINK, Peter Kevin (Orgs.).

Reforma do Estado e Administração Pública Gerencial. Rio de Janeiro: FGV, 2006.

LANE, Jan Erik. The public sector: concepts, models and approaches. London: Sage, 1993.

MARTINS, Humberto Falcão. Ética do Patrimonialismo e a Modernização da Administração Pública Brasileira. In: MOTTA, Fernando C. Prestes; CALDAS, Miguel P. Cultura Organizacional e Cultura Brasileira. São Paulo: Atlas, 1997.

MENDES, Vera Lúcia Peixoto S.; TEIXEIRA, Francisco Lima C. O novo gerencialismo e os desafios para a administração pública. In: Encontro da associação nacional dos programas de pós-graduação em administração (EnANPAD), 24, 2000, Florianópolis. Anais eletrônicos... Santa Catarina: ANPAD, 2000. 
ORMOND, Derry; LÖFFLER, Elke. A nova gerência pública. In: RSP Revista do Serviço Público. Ano 50, n. 2, abr./jun. p. 66-96, 1999.

PAULA, Ana Paula Paes de. Por uma nova gestão pública: limites e potencialidades da experiência contemporânea. Rio de Janeiro: Editora FGV, 2008.

PEREIRA, Luiz Carlos Bresser. Gestão do setor público: estratégia e estrutura para um novo Estado. In: PEREIRA, Luís Carlos Bresser; SPINK, Peter Kevin (Orgs.). Reforma do Estado e Administração Pública Gerencial. Rio de Janeiro: FGV, 2006.

POLLITT, Christopher. Antistatist Reforms and the New Administrative Directions: Public Administration in the United Kingdom. Public Administration Review,v. 56, jan./feb. p. 81-8, 1996.

SEABRA, Sérgio Nogueira. A nova administração pública e mudanças organizacionais. In: RAP - Revista de Administração Pública, jul/ago 2001, p. 19-43. Rio de Janeiro: FGV/EBAPE - Escola Brasileira de Administração Pública e de Empresas. Disponível em: <http:// www.ebape.fgv.br/academico/asp/dsp_rap_resumos.asp?cd_artigo $=639>$. Acesso em: 27 jan. 2010.

SECCHI, Leonardo. Modelos organizacionais e reformas da administração pública. In: RSP - Revista de Administração Pública, mar./abr. v. 43. Rio de Janeiro: Fundação Getúlio Vargas, 2009.

TRAGTENBERG, Maurício. Burocracia e ideologia. São Paulo: Editora UNESP, 2006.

WEBER, Max. Economia e sociedade. Brasília: Editora da UnB, 1999.1 v. 